\title{
Formação de professores em geotecnologia por meio de ensino a distância
}

\section{Teacher training in geotechnologies using distance education}

\author{
Teresa Gallotti Florenzano ${ }^{1}$ \\ Suely Franco Siqueira Lima ${ }^{2}$ \\ Elisabete Caria Moraes ${ }^{3}$
}

\begin{abstract}
RESUMO
O sensoriamento remoto e o Sistema de Informações Geográficas (SIG) são recursos didáticos de grande potencial para diferentes áreas e níveis de ensino. Para capacitar professores no uso dessas geotecnologias foram criados dois cursos a distância. O objetivo deste artigo é apresentar os resultados obtidos com esse tipo de capacitação oferecida a professores de escolas da rede pública e privada do Brasil. Para ensinar técnicas de processamento de imagens e SIG, foram preparados para os professores tutorias específicos, bem detalhados. Os materiais e os métodos utilizados mostraram-se adequados, apesar de somente cerca de $50 \%$ dos professores terem alcançado um bom desempenho nas atividades propostas. Os resultados obtidos mostraram a necessidade de se investir não só na formação continuada, mas também na formação inicial dos professores.
\end{abstract}

Palavras-chave: formação de professores; educação básica; sensoriamento remoto; SIG; educação a distância.

1 Doutora em Geografia Física. Instituto Nacional de Pesquisas Espaciais (INPE). São José dos Campos, Brasil.

2 Mestre. em Ciências Ambientais. Instituto Nacional de Pesquisas Espaciais (INPE). São José dos Campos, Brasil.

3 Doutora em Meteorologia. Instituto Nacional de Pesquisas Espaciais (INPE). São José dos Campos, Brasil. 


\begin{abstract}
Remote Sensing and Geographic Information System (GIS) are very powerful tools for instructional use in different subject areas and by different school levels. For the in-service teacher training in the use of these geotechnologies two distance educations courses were created. The objective of this paper is to present the results obtained with this type of training offered to teachers of public and private schools from Brazil. Specially well-organized tutorials for guiding teachers on digital image processing techniques and GIS were made available for them. The material and method used has proved to be suitable, although only about $50 \%$ of the teachers had a good performance in the tasks proposed. The results showed the need to promote not only in-service teacher training courses but also pre-service teacher training.
\end{abstract}

Keywords: in-service teacher training; elementary and high school; remote sensing; GIS; distance education.

\title{
Introdução
}

Na opinião da maioria dos educadores, as instituições de ensino não podem mais ignorar o potencial dos novos recursos tecnológicos e didáticos na educação. Segundo Gabini e Diniz (2009), a escola deve-se abrir às possibilidades geradas pelas tecnologias para não se distanciar das novas linguagens. Isso é ressaltado também nos Parâmetros Curriculares Nacionais [...]

[...] quando o professor utiliza um recurso tecnológico, como fonte de informação ou como um recurso didático para a atividade de ensino, está também possibilitando que os alunos aprendam sobre as práticas sociais que utilizam tecnologia e desenvolvam habilidades e atitudes para se relacionarem com a tecnologia na vida (BRASIL, 1998).

Não basta, no entanto, inserir o uso de tecnologia na proposta curricular, pois, como destacam Gontijo e Costa (2008), a simples adoção de computadores e outros recursos tecnológicos nas salas de aulas não garante inovações pedagógicas e resultados sempre positivos. Nesse sentido, Valente (2002) também salienta que o uso da internet, ou do computador, por exemplo, não é garantia 
para que o aluno construa conhecimento. Cabe ao professor saber explorar os potenciais educacionais oferecidos por esses recursos e criar situações para que o aluno possa significar e compreender a informação obtida, gerando novos conhecimentos. Concorda-se com esses autores que a introdução de novas tecnologias deve ser ancorada em propostas pedagógicas e programas de formação de professores. Considerando a escassez de recursos e as dimensões do Brasil, que dificultam o acesso à informação e formação, é fundamental investir em educação a distância para a formação continuada de professores. A educação a distância, como salienta Pedrosa (2003), ajuda os professores a vencer as barreiras do tempo, do espaço e da falta de recursos financeiros. A educação a distância é um modelo educativo que aplica a tecnologia no processo de aprendizagem, supera os limites de lugar e tempo e proporciona grande flexibilidade. Ela promove o desenvolvimento de novas metodologias, levando professores e alunos a assumirem novos papéis e novas atitudes. Para ser eficiente, a educação a distância deve envolver interatividade entre professores e alunos, entre alunos e o ambiente de aprendizado, e entre os próprios alunos.

Nesse contexto se insere o trabalho dos autores que vêm investindo nessa modalidade de ensino desde 2004 e têm como desafio a busca por um padrão de educação a distância de qualidade. Esta depende não apenas da qualidade do material e da metodologia utilizados, mas da proposta pedagógica e da interação professor-aluno, ou seja, daquilo que Valente (2002) e Valente (2003) chamam de estar junto virtual.

O estar junto virtual envolve múltiplas interações no sentido de acompanhar e assessorar constantemente o aprendiz para poder entender o que ele faz e, assim, propor desafios que o auxiliem a atribuir significado ao que está desenvolvendo. Estas interações criam meios para o aprendiz aplicar, transformar e buscar outras informações e, assim, construir novos conhecimentos (VALENTE, 2003, p. 31).

O "estar junto virtual" pode ser propiciado pelo aluno engajado na resolução de um problema ou projeto. Dessa forma, a capacitação realizada e discutida neste artigo, foi orientada por uma proposta educativa baseada na metodologia da pedagogia de projetos que engloba os projetos pedagógicos a serem desenvolvidos pelos professores junto a seus alunos (EVENSON; HMELO, 2000). O programa de capacitação de professores desenvolvido pelo INPE, desde 1998, curso presencial, e desde 2009, na modalidade à distância, não visa à técnica pela técnica, e sim entende este recurso tecnológico como um importante ins- 
trumento de apreensão da realidade que permite a professores e alunos, como cidadãos não excluídos da era digital e do conhecimento, intervirem em seu meio na busca de um desenvolvimento sustentável. Esse tipo de capacitação, de acordo com Santos (2003), incorpora conceitos relacionados a uma pedagogia mais dinâmica, profundamente articulada em torno da criatividade, da motivação intrínseca, da autoavaliação e da construção ativa de conhecimentos.

Além da internet e do computador, utilizados na capacitação à distância, as tecnologias abordadas neste artigo são Sensoriamento Remoto e SIG (Sistema de Informações Geográficas). Estas, junto com o GPS (Global Positioning System, Sistema de Posicionamento Global), formam o conjunto denominado geotecnologias.

O sensoriamento remoto é a tecnologia de aquisição de dados à distância, por meio de sensores instalados em plataformas terrestres, aéreas e orbitais (satélites artificiais). Grande parte dos dados obtidos de satélite é processada em forma de imagens, que podem ser utilizadas no estudo e no monitoramento de vários objetos (florestas, culturas agrícolas, cidades etc.) e fenômenos (meteorológicos, erosão, desmatamento, queimadas etc.) da superfície terrestre. Existem muitas outras possibilidades de exploração desses dados, incluindo o seu uso didático para diferentes conteúdos curriculares e de forma interdisciplinar (FLORENZANO, 2007).

O SIG é um sistema computacional que permite armazenar, integrar, analisar, visualizar informações de diferentes tipos e representá-las em forma de mapas. Um exemplo simples e bem conhecido de SIG é o do software Google Earth, que permite superpor vários planos de informação (mapas, malha viária, toponímia, além de calculo de distâncias etc.) ao mosaico de imagens de satélite do globo terrestre.

$\mathrm{Na}$ medida em que o SIG possibilita integrar, analisar e espacializar (gerar mapas) informações locais, regionais e globais, ele torna-se um poderoso recurso para várias aplicações, incluindo a didática. $\mathrm{O}$ educador pode utilizar o sensoriamento remoto e o SIG para inserir seu aluno no mundo tecnológico, tornar suas aulas mais dinâmicas e interessantes, bem como gerar seu próprio material didático para estudo do espaço local, de vivência do educando. Essas tecnologias dão a oportunidade ao educador e educando de elaborar material que complemente os livros didáticos, de ligar o local com o global e gerar conhecimento (LIMA et al., 2009; MORAES; FLORENZANO; LIMA, 2009; FLORENZANO, 2007; KIRMAN, 2000).

Em 2004 um grupo de pesquisadores do INPE, que inclui os autores deste artigo, com o objetivo de difundir geotecnologia e desenvolver novas metodologias de ensino, usando sistemas de educação a distância, criou um programa de formação de professores. Inicialmente optou-se pela capacitação de professores 
universitários devido ao seu papel de multiplicador e pela disponibilidade de infraestrutura computacional existente nas universidades. Em 2007 (de agosto a novembro) foi realizado um curso semipresencial (I Curso de Atualização em Sensoriamento Remoto e Sistemas de Informação Geográfica para Professores da Educação Básica), na Diretoria de Ensino da Região de São José dos Campos com o apoio do INPE. Com base nessa experiência bem-sucedida (LIMA et al., 2009), em 2009 o programa de capacitação do INPE foi expandido para os professores do ensino básico. O tutorial utilizado no curso semipresencial foi adaptado para os cursos a distância avaliados neste artigo. Nesse contexto, o objetivo deste artigo é apresentar a avaliação das duas edições da capacitação, a distância, em geotecnologia, voltada para os professores do ensino básico, que utilizou a metodologia de projetos e exercitou o "estar junto virtual". Apesar de a própria experiência e a literatura indicarem mais eficiência no uso do modelo híbrido (semipresencial), optou-se pelo ensino totalmente à distância visando atingir o professor das regiões afastadas dos grandes centros.

\section{Metodologia}

O ambiente de ensino a distância utilizado é o sistema TelEduc, desenvolvido por pesquisadores do Núcleo de Informática Aplicada à Educação - NIED (http://hera.nied.unicamp.br/teleduc) e pelo Instituto de Computação (IC) da Universidade Estadual de Campinas-UNICAMP, visando à formação de professores. Por isso, por se um software livre e fácil de usar, ele foi selecionado para capacitar os professores em geotecnologia.

O software utilizado para a prática de geotecnologia é o SPRING (Sistema de Processamento de Informações Georreferenciadas). Este é um software livre, desenvolvido pelo INPE (CÂMARA et al., 1996), que tem funções de processamento de imagens digitais e SIG. A versão utilizada nos cursos foi a do SPRING 5.1.2.

Em relação ao material didático, foram utilizados: o livro o livro "Iniciação em Sensoriamento Remoto" (FLORENZANO, 2007), o CD educacional "Sensoriamento Remoto: Aplicações para a preservação, conservação e desenvolvimento sustentável da Amazônia" (DIAS et al., 2009) e tutorias. Este cd interativo (contém textos, exercícios, atividades, testes, visitas virtuais, fotos, áudio, músicas, tabelas, bloco de anotações, figuras ilustrativas e imagens de sensores remotos) traz uma Introdução ao Sensoriamento Remoto; Princípios de Preservação e Conservação, que destaca os ecossistemas amazônicos; Estudos 
de caso na Amazônia - Exemplos do LBA (Experimento de Grande Escala da Biosfera-Atmosfera na Amazônia).

O livro fornece, em linguagem simples, informações básicas de sensoriamento remoto: ilustra como são obtidas as imagens de satélites, descreve os tipos de sensores e satélites existentes e destaca o programa espacial brasileiro. Aborda a relação entre imagem e mapa e o processo de interpretação de imagens obtidas por sensoriamento remoto. Ele mostra como as imagens de satélites podem contribuir para o estudo de fenômenos ambientais, de ambientes naturais e daqueles transformados pelo homem, além de destacar o uso do sensoriamento remoto como recurso didático multi e interdisciplinar.

Os tutoriais foram inicialmente desenvolvidos para um curso semipresencial de capacitação de professores (LIMA et al., 2009). Este material traz o "passo a passo" dos procedimentos para: utilizar o TelEduc; adquirir o software Spring e imagens dos satélites Cbers (sino-brasileiro) e Landsat (americano), disponíveis gratuitamente nos sites do INPE (http://www.dgi.inpe.br/CDSR/) e da NASA (http://glcfapp.glcf.umd.edu:8080/esdi/index.jsp); criar banco de dados, projeto e plano de informação; importar imagens para o Spring, realçar e georreferenciar (ajustar a uma base cartográfica) imagens de satélite; classificar imagens; editar texto; calcular métricas; gerar mapas; elaborar projeto.

A inscrição dos professores nos dois cursos oferecidos foi realizada por meio do endereço eletrônico (http://www.selperbrasil.org.br/cursos/ead/geo_ensino/index.html) com os seguintes requisitos: ser profissional da Educação Básica (ensino fundamental e médio de escola pública e privada) de qualquer área do conhecimento, estar em atividade (sala de aula), e possuir internet com Banda Larga. A seleção dos candidatos, para as 30 vagas oferecidas, levou em conta também a distribuição geográfica e a dificuldade de acesso à informação. O primeiro curso ocorreu no segundo semestre de 2009 (de agosto a outubro) e o segundo no primeiro semestre de 2010 (de março a maio). A carga horária do curso foi de 104 horas (13 semanas), com dedicação média do aluno de 8 horas semanais durante o período do curso, com a recomendação de três horas por semana para leitura (aulas) e cinco horas para as atividades.

As aulas foram agrupadas em dois módulos. No módulo I as aulas abordaram os seguintes tópicos: Fundamentos de Sensoriamento Remoto; Interpretação de Imagens; Orientação para Elaboração de Projetos com uso de Geotecnologia; Exemplos de uso da Geotecnologia na Educação, no Estudo de Fenômenos e Ambientes Terrestres. Para cada um desses assuntos os formandos desenvolveram atividades. No módulo II, com base nos tutoriais, os formandos realizaram atividades de: aquisição do Spring e de imagens de satélite, processamento das imagens digitais (leitura, realce, georreferenciamento e classificação de imagens) e uso de SIG (edição de texto, operações métricas e geração de 
mapa). Paralelamente à realização das atividades do segundo módulo, teve início o desenvolvimento do projeto (tema livre). Com o objetivo de incentivar os professores a socializarem os resultados obtidos com o projeto, bem como a participar de eventos (congressos, simpósios etc.), receberam também um tutorial sobre como escrever um artigo científico.

Após o término do curso, os formandos tiveram mais dois meses para concluir o projeto e colocar em prática o conhecimento adquirido no curso. Durante esse período eles contaram com a ajuda dos formadores por meio do TelEduc. Na interação entre formadores e formandos foram utilizadas as ferramentas "Correio" e "Portfólio", do ambiente TelEduc. A ferramenta "Bate-papo", voltada para sessões síncronas, não foi utilizada, devido à baixa participação de alunos observada nos cursos a distância realizados pelo programa do INPE.

Os professores foram avaliados por meio das atividades realizadas durante todo o curso e com base no projeto desenvolvido com seus alunos. $\mathrm{O}$ ambiente TelEduc, o software Spring, o material didático e os formadores também foram avaliados pelos formandos, por meio de um questionário. Este incluía uma autoavaliação dos formandos e solicitava a eles críticas e sugestões para o aperfeiçoamento do curso. Procurou-se manter a mesma metodologia para os dois cursos, para efeito de comparação dos resultados. Por isso, falhas identificadas na primeira edição não foram corrigidas para a segunda. Os alunos que realizaram pelo menos $70 \%$ das atividades e realizaram o projeto receberam um certificado do INPE.

\section{Resultados e discussão}

O número total de inscrições recebidas no primeiro curso $\left(2 .^{\circ}\right.$ semestre de 2009) foi de 290, enquanto que o segundo (1. ${ }^{\circ}$ semestre de 2010) esse número caiu para 75. Essa redução pode ser explicada pelo tempo menor de divulgação e inscrição da segunda edição do curso, além de coincidir com período de férias (dezembro/janeiro). É uma explicação pertinente, considerando os pedidos que o Inpe vem recebendo, de professores de várias regiões do Brasil, por uma nova edição do curso. Todos os estados brasileiros, além do distrito federal, tiveram participantes no curso, considerando as duas edições. Verificou-se que a maioria dos professores ( $85 \%$ ) era da área de geografia, mais diretamente beneficiada pelas geotecnologias, e de escola pública (90\%), de certa forma priorizada no processo de seleção dos professores. Dos 18 professores (entre os 30 selecionados) que se matricularam na primeira edição (2009), 11 realiza- 
ram o projeto nas escolas, mas somente oito (8) realizaram todas as atividades mais o projeto, concluindo o curso com sucesso. Dos 25 professores (entre os 30 selecionados) que se matricularam na segunda edição (2010), 13 realizaram o projeto nas escolas, mas somente 10 realizaram todas as atividades mais o projeto, concluindo o curso com sucesso.

Comparando esses resultados com aqueles obtidos por Lima et al. (2009) por meio do curso semipresencial, verifica-se, como era de se esperar, e destacado anteriormente, que esta modalidade é mais eficiente. Na capacitação semipresencial $84 \%$ dos professores concluíram (incluindo a realização do projeto na escola) o curso com sucesso, enquanto na capacitação totalmente à distância esse percentual foi inferior a 50\% (44\% em 2009 e 40\% em 2010).

Quanto à avaliação do curso, somente $70 \%$ dos professores preencheram a avaliação e alguns não responderam todas as questões. Pelas respostas obtidas, verificou-se que $37 \%$ dos professores já haviam realizado curso a distância; $40 \%$ tiveram dificuldade para usar o ambiente do TelEduc; $70 \%$ tiveram dificuldade para uso do software SPRING; para 30\% a quantidade de conteúdo abordado foi muita; $57 \%$ classificaram o material do curso como ótimo e $10 \%$ como bom; $80 \%$ consideraram o desempenho dos formadores ótimo e $20 \%$ bom; $37 \%$ consideraram a duração do curso suficiente, enquanto para $30 \%$ foi curta; $60 \%$ consideraram viável o uso do SPRING na escola e 57\% conseguiram usar geotecnologia na sua prática pedagógica.

Nos cursos para professores do ensino superior e demais profissionais que o INPE oferece na modalidade à distância, o ambiente TelEduc tem sido considerado por praticamente todos os formandos muito eficiente e amigável. A dificuldade encontrada pelos professores do ensino básico com este software se deve provavelmente à pouca familiaridade com o computador que ainda existe entre eles, principalmente daqueles formados há mais tempo. Isso explica também a dificuldade de utilizar o SPRING, embora este seja um software menos amigável.

Como nos demais cursos realizados, os materiais utilizados tiveram a aprovação da maioria dos formandos. No caso específico dos tutoriais utilizados nestes dois cursos, eles podem ser considerados eficientes com base na opinião dos professores e no seu desempenho na utilização do SPRING. Isso é verdade se considerada a dificuldade de processar imagens com um software não muito amigável e desconhecido dos professores. Verificou-se, no entanto, que os tutoriais podem ser melhorados se feitos alguns ajustes, complementados com informações teóricas sobre os processamentos e atualizados para a nova versão do SPRING 5.1.7, mais robusta e amigável.

Desse modo, o trabalho dos formadores também poderá ser facilitado e exigir menos tempo. Poderia se pensar inclusive em diminuir a duração do curso, 
apesar de considerada curta por uma parcela expressiva de alunos. O "estar junto" foi efetivamente praticado durante os cursos. A interação formador-formando foi promovida pelas próprias atividades e o projeto propostos no curso. A dificuldade na realização dessas atividades exigiu uma interação constante e muita dedicação de formadores e formandos. Essa prática impede a capacitação de um grande número de professores (acima de 25), mas certamente amplia a qualidade da formação promovendo um crescimento de todos os envolvidos no processo.

Os resultados obtidos com essas duas capacitações, embora numericamente não muito significativos, em termos de qualidade podem ser considerados muito bons. Os professores que superaram as dificuldades conseguiram obter ótimos resultados e gerar conhecimento junto com seus alunos. Isso foi facilitado pelo desenvolvimento de projetos pedagógicos, confirmando sua eficiência destacada por Evenson e Hmelo (2000) e Santos (2003). Entre os motivos que explicam o insucesso da maioria dos professores pode-se destacar: deficiência na formação inicial, incluindo informática; configuração da máquina utilizada (não atendia às especificações mínimas necessárias para utilizar o SPRING); pouco tempo disponível para as atividades; infraestrutura escolar deficiente (incluindo apóio da direção da escola), entre outras. Além disso, as atividades tinham certo encadeamento, por exemplo, sem aquisição das imagens, sem e com georrefenciamento (ajustadas a uma base cartográfica), não era possível realizar as demais atividades. Um exemplo de atividade realizada por professor durante o curso é apresentada na figura 1 . 


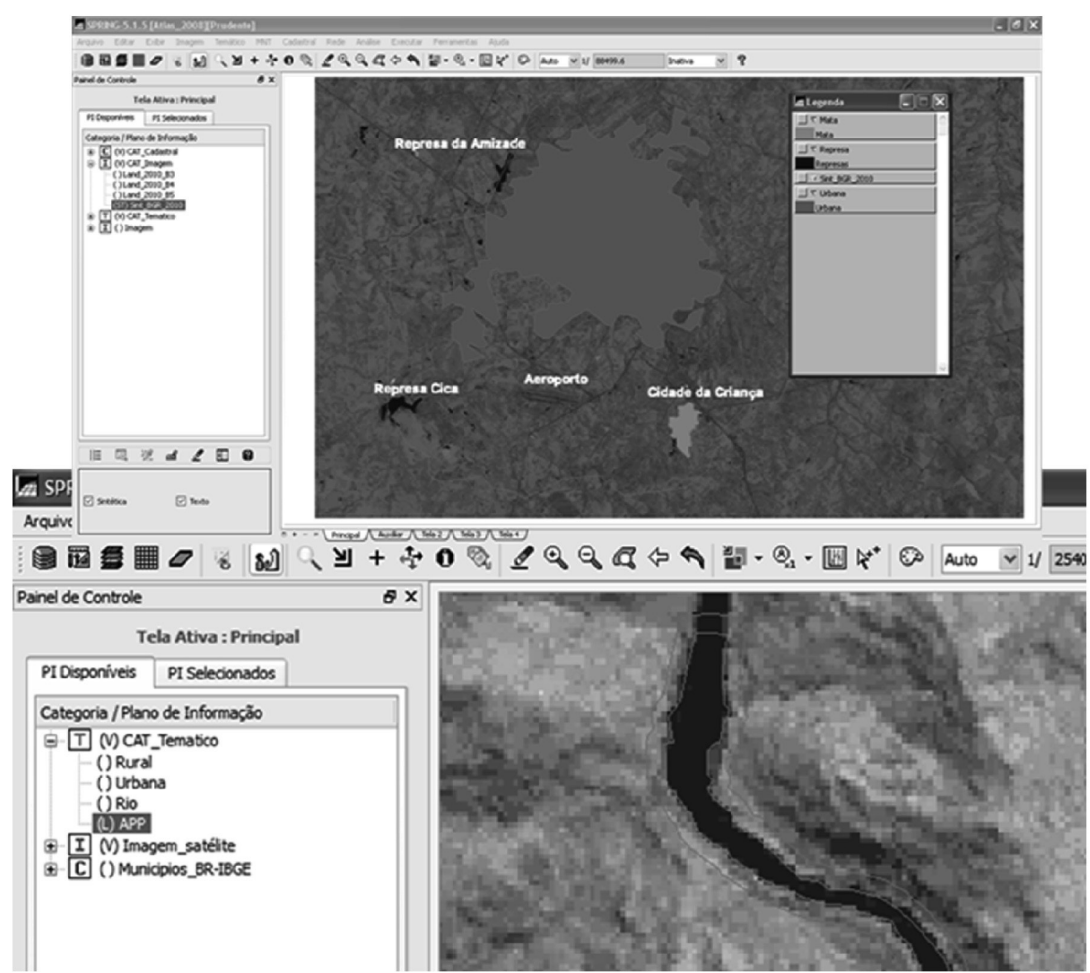

Figura 1 - Exemplo de classes temáticas e APP (Área de Proteção Ambiental) de drenagem, geradas por professor com uso do SPRING e imagens Landsat, atividades realizadas durante o curso de 2010

A pouca familiaridade com o computador, por parte de muitos professores ainda é uma limitação no uso de geotecnologia. Esse aspecto, entre outros, foi ressaltado por professores na sua autoavaliação:

Considero que, em face aos meus conhecimentos, a evolução foi significativa. Detectei limites de operabilidade, mas que julgo devase ao meu baixo conhecimento. Acredito que com algum tempo de prática será possível evoluir para os níveis mais técnicos, necessários ao desenvolvimento de bons trabalhos.

faltou tempo e dedicação da minha parte, ainda tenho certa dificuldade em trabalhar com computador, apesar de querer aprender a trabalhar com spring. 
...realizei o projeto na escola e obtive um resultado que considerei bom, diante de todas as dificuldades de uma escola rural com público carente.

No início do curso estive mais em dia com as atividades. à medida que estas foram ficando mais complexas e devido a alguns problemas técnicos (meu pc e notebook) tive alguns atrasos, porém não desisti.

...tive sérios problemas com o software instalei varias vezes em meu pc, tive sérios problemas para processar as imagens não aproveitei nada. Aproveitei só até o momento em que fiz meu projeto depois que o resto das atividades eram realizadas no spring não aproveitei mais nada só tive dor de cabeça e desanimo. Acabei aplicando o meu projeto na escola utilizando a internet e buscando imagens do google earth, pois não consegui as georreferenciadas e muito menos trabalhar com o programa. Outro fator consegui somente realizar três atividades sei que fui reprovado mais valeu a experiência desastrosa mesmo assim envio o artigo. Palavras sinceras de um professor que não obteve resultados positivos. Agradeço a todos os formadores pela a atenção e digo sinceramente o meu insucesso não foi culpa de vocês, nem falta de vontade minha, foi a falta de recursos materiais de minha parte mesmo.
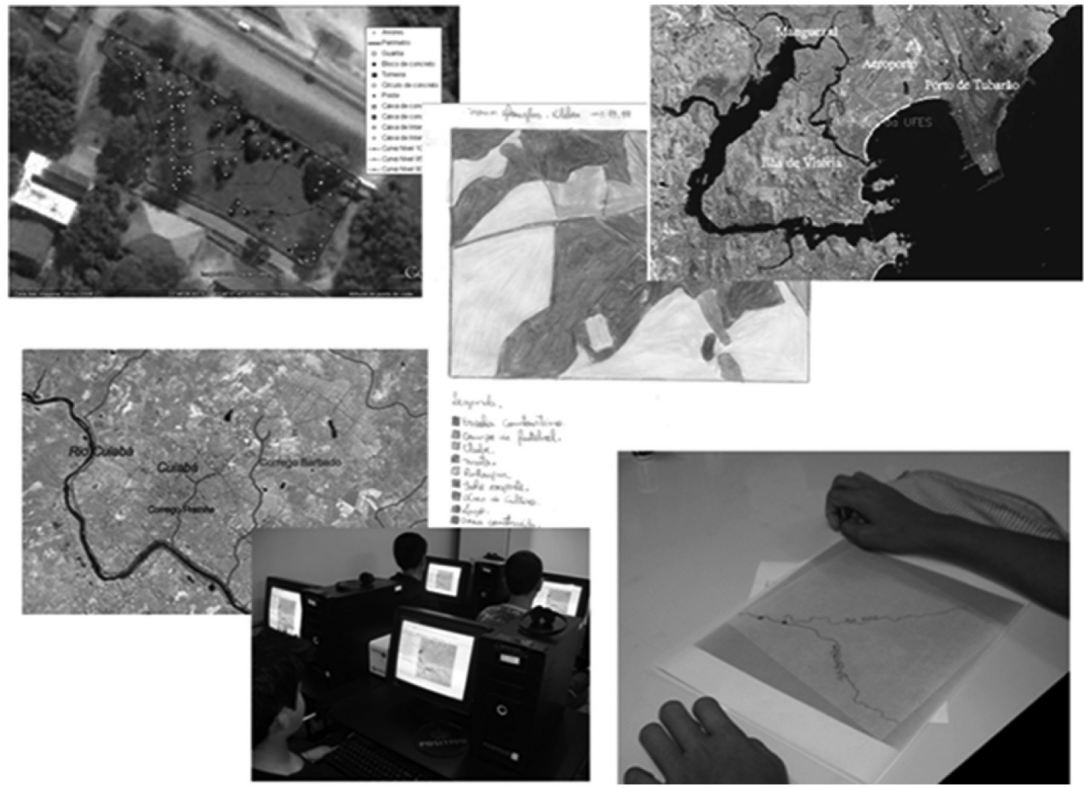

Figura 2 - Exemplos de atividades realizadas pelos alunos nos projetos desenvolvidos na escola com os professores (cursos 2009 e 2010). 
Em relação aos projetos desenvolvidos com os alunos na escola, como a maioria dos professores era da área de geografia, foram abordados temas relacionados com os conteúdos desta disciplina e questões ambientais (paisagem, processo de favelização, crescimento urbano vertical, expansão urbana e crescimento populacional, características do continente americano, manguezal, desmatamento da Amazônia, áreas de preservação ambiental, índice de área verde (contagem de árvores). O estudo de questões ambientais, além de ser uma demanda em geral da própria escola, é favorecido pelo uso de geotecnologia. Isso é válido também para outro aspecto bastante explorado, o multitemporal, ou seja, a análise da dinâmica (evolução da ocupação) da paisagem, confirmando trabalhos anteriores (LIMA et al., 2009; MORAES; FLORENZANO; LIMA, 2009; FLORENZANO, 2007; KIRMAN, 2000). Exemplos de atividades realizadas pelos alunos nos projetos desenvolvidos na escola são mostrados na figura 2 .

Por falhas na formação inicial, verificou-se que a grande maioria dos professores teve muita dificuldade de escrever o projeto (objetivo, material e método e, principalmente, os resultados obtidos). Muitos desses professores foram formados em uma época em que a monografia (TCC) ainda não era exigida e o uso do computador era pouco difundido. Além disso, é utilizada outra formatação nos projetos pedagógicos desenvolvidos nas escolas da rede pública, à qual está ligada a maioria dos formandos dos cursos abordados neste artigo. Essa dificuldade explica por que muitas práticas pedagógicas bem-sucedidas não são socializadas, publicadas em anais de eventos e revistas especializadas.

Todos os professores que desenvolveram projeto na escola destacaram como positivo o envolvimento, a motivação e o aprendizado dos alunos. Eles concordam com a demanda e necessidade de usar novas tecnologias no ensino e mostraram interesse em prosseguir, melhorar, se aprofundar nesses recursos, como poder ser constatado por algumas conclusões dos professores, apresentadas a seguir:

Foi observado uma participação grande dos alunos e o interesse de conhecer melhor sua cidade de um ponto de vista diferente. Professor do Colégio Jean Piaget, Santos-SP.

A partir do desenvolvimento desse trabalho, foi possível analisar que é crescente a necessidade de incorporação das Geotecnologias ao ensino, destacadamente pela Geografia, cujos conteúdos podem ser profundamente auxiliados por essas inovações. Os estudantes mostram-se mais interessados e atentos quando apresentados a aulas mais dinâmicas, que fazem uso de diferentes recursos para o ensino. O processo ensino-aprendizagem ganha mais qualidade, gerando resultados mais satisfatórios. Professora 
de geografia do Instituto Federal de Educação, Ciência e Tecnologia da Paraíba - IFPB, João Pessoa, Paraíba.

Este projeto foi relevante e nos surpreendeu também em outros pontos como: pela assiduidade, compromisso e participação dos alunos; a facilidade com a qual os alunos tiveram em entender em um nível básico as imagens; a interação social que ocorreu entre eles. As mudanças nas práticas pedagógicas geográficas contribuirão e muito para a melhoria na educação e logicamente correlacionar esta aprendizagem a outras áreas da ciência dentro do ensino básico. Professora da Escola Estadual Irmã Gislene, Patrocínio-MG.

Foi perguntado aos alunos se gostaram de trabalhar com imagens de satélites e todos responderam que "sim" e justificaram de diferentes formas, com destaque para maior conhecimento da área, é algo interessante e permite uma visão melhor do espaço, bem como, destacaram que gostariam de realizar outras atividades usando os produtos de Sensoriamento remoto. $\mathrm{O}$ entendimento dos alunos sobre o problema ambiental destacado pela maioria da turma confirma a idéia de que os produtos de Sensoriamento Remoto são excelentes recursos na formação de alunos conscientes, críticos e sujeitos de sua história. Professora Escola Municipal de Ed. Inf. E Ens. Fud. Prof. a Donatila Santana Lopes, Belém-PA.

Merecem destaque ainda comentários de alunos enviados pela professora da Unidade Escolar Professora Helena Carvalho, Teresina-PI:

Aprendi que a palavra sensoriamento remoto está ligado a satélites.

Muitos mapas são feitos a partir de imagens de satélites e que cada pessoa pode fazer um mapa.

Os satélites nos fornecem outras informações não somente a identificação de lugares.

É interessante que o Brasil tenha um satélite, eu não sabia que estávamos tão avançado.

Pela imagem podemos perceber as curvas do rio Poti e Parnaíba.

Devido principalmente a problemas de infraestrutura nas escolas e tempo para desenvolver o projeto com os alunos, a maioria dos professores optou por 
utilizar imagens já processadas, por exemplo, as do mosaico do Google Earth e as do projeto da Embrapa "Brasil visto do Espaço" (www.cnpm.embrapa.br), entre outros. A utilização dessas imagens e a consulta a bancos de dados existentes pode ser uma alternativa para os professores que não conseguirem buscar e pocessar dados originais, utilizando um software como o SPRING. Ocorre que nesses casos os dados e as imagens são de uma determinada data e (ou) não abrangem todas as áreas de interesse. Por isso, vale a pena o professor aprender a adquirir as imagens originais (nos sites do INPE e da NASA) e a processá-las. Desse modo, ele terá a oportunidade de selecionar e processar imagens de várias datas e estudar com seus alunos as transformações que ocorrem no seu município, região ou área de interesse. Além disso, eles podem criar o próprio banco de dados e gerar novas informações.

\section{Considerações finais}

A formação de professores por meio de modelos presenciais e híbridos pode ser mais eficiente do que a realizada com ensino (totalmente) à distância. Porém o alcance geográfico (espacial), em um país de dimensões continentais e carente de recursos como o Brasil, da modalidade de ensino á distância é inigualável. Apesar de menos da metade dos professores ter concluído o curso com sucesso, a qualidade dos resultados obtidos por eles indica a viabilidade do ensino a distância nesse tipo de capacitação. Para superar as dificuldades observadas, as políticas públicas voltadas para a educação devem promover uma formação inicial e continuada de qualidade para os professores do ensino básico. Não devem se esquecer também da infraestrutura, do ambiente e da comunidade escolar como um todo para que o professor tenha condições de aplicar os conhecimentos adquiridos e inovar sua prática pedagógica.

\section{REFERÊNCIAS}

BRASIL. Ministério da Educação e do Desporto Secretaria da Educação Fundamental. Parâmetros Curriculares Nacionais: Temas Transversais. Brasília: MEC/SEF, 1998. 
CÂMARA, G. et al. SPRING: Integrating remote sensing and GIS by object-oriented data modelling. Computers \& Graphics, v. 20, n. 3, p. 395-403, May-June 1996.

DIAS, N. W. et al. Sensoriamento remoto: aplicações para a preservação, conservação e desenvolvimento sustentável da Amazônia. 2.ed. rev. e ampl. São José dos Campos: Inpe, 2009. (CD-ROM).

EVENSON, D. H.; HMELO, C. E. Problem-based learning: a research perspective on learning interactions. Mahwah, NJ: Blackwell Publishers, 2000.

FLORENZANO, T. G. Iniciação em sensoriamento remoto. 2.ed. de imagens de satélite para estudos ambientais. São Paulo: Oficina de Textos, 2007.

GABINI, W. S.; DINIZ, R. E. da S. Os professores de química e o uso do computador em sala de aula: discussão de um processo de formação continuada. Ciência \& Educação, v. 15, n. 2, p. 343-58, 2009.

GONTIJO, F. L.; COSTA, J. W. Uma experiência com software educativo na escola: a tecnologia e a prática pedagógica em discussão. Educação \& Tecnologia, v. 13, n. 2, p. 96-100, 2008.

KIRMAN, J. M. Remote Sensing and the Elementary Child. Geocarto International, v. 15, n. 4 , p. $69-72,2000$.

LIMA, S. F. S. et al. Formação de professores da educação básica em geotecnologias. In: SIMPÓSIO BRASILEIRO DE SENSORIAMENTO REMOTO - SBSR, 14., 2009, Natal. Anais... São José dos Campos: INPE, 2009. p. 2437-2444. Disponível em: $<$ http://urlib.net/dpi.inpe.br/sbsr@80/2008/11.17.12.01>. Acesso em: 04 mar. 2010.

MORAES, E. C.; FLORENZANO, T. G.; LIMA, S. F. S. Formação de professores dos ensinos fundamental e médio em Sensoriamento Remoto: Onze anos de Experiência do INPE. In: SIMPÓSIO BRASILEIRO DE SENSORIAMENTO REMOTO - SBSR, 14., 2009, Natal. Anais... São José dos Campos: INPE, 2009. p. 2451-2458. Disponível em: <http://urlib.net/dpi.inpe.br/sbsr@80/2008/11.18.00.57>.Acesso em:04 mar. 2010.

PEDROSA, S. M. P. A. A educação a distância na formação continuada do professor. Educar em Revista, Curitiba, n. 21, p. 67-81, 2003.

SANTOS, G. L. A gestão de relações educativas apoiadas pelo computador por meio da pedagogia de projetos. In: professores. Brasília: Plano, 2003. Cap. 3.

(Org.). Tecnologias na educação e formação de

VALENTE, J. A. Uso da internet em sala de aula. Educar em Revista, Curitiba, n. 19, p. 131-146, 2002. 
VALENTE, J.A. Curso de especialização em desenvolvimento de projetos pedagógicos com o uso das novas tecnologias: Descrição e fundamentos. In: VALENTE, J.A.; PRADO, M.E.B.B; ALMEIDA, M.E. B. (orgs); Educação a Distância Via Internet. São Paulo: Avercamp, 2003. p. 23-55.

Texto recebido em 12 de abril de 2011

Texto aprovado em 22 de abril de 2011. 